\title{
Improvement Strategy Selection in FMEA: Classification, Review and New Opportunity Roadmaps
}

\author{
Agung Sutrisno \\ Department of Mechanical Engineering \\ Sam Ratulangi University, Manado, North Sulawesi, Indonesia 95115 \\ E-mail address: a6un6sutrisno@yahoo.com (Corresponding Author) \\ Hyuck Moo Kwon \\ Department of Systems Management and Engineering \\ Pukyong National University, Busan, South Korea \\ E-mail address: iehmkwon@ @knu.ac.kr \\ Tzong-Ru (Jiun-Shen) Lee \\ Department of Marketing Management \\ National Chung Hsing University, Taiwan \\ E-mail address:trlee@dragon.nchu.edu.tw \\ Jang Hyon Ae \\ Department of Systems Management and Engineering \\ Pukyong National University, Busan, South Korea \\ E-mail address: ie-jha@pknu.ac.kr
}

\begin{abstract}
Failure risk reprioritization and improvement strategy selection are two inseparable parts in FMEA methodology. Nevertheless, the previous studies on the new research opportunities provide very scanty discussions on the latter part. This paper presents an initial survey to classify literature related to improvement strategy selection methodology in FMEA. Systematic literature review using various reference databases is undertaken. Driven by new paradigms and recent trends on managing business operation, many studies have been dedicated to advance improvement strategy selection based on FMEA. The result of our survey, however, indicated that all those previous endeavours do not seem to be sufficient. Based on some observable gaps from the previous references, new research roadmaps in selecting improvement efforts are presented.
\end{abstract}

Keywords: FMEA, RPN, Corrective Action, SWOT, Supply Chain

\section{INTRODUCTION}

Under higher customers' requirement for improving design/manufacturing and service quality delivery, improving methodology for risk-based improvement strategy selection is important for sustaining business operation. In industrial practice, FMEA is used as means for appraising the risk due to occurrence of critical failures. Introduced in $1950 \mathrm{~s}$, it is an engineering tool aimed to identify potential and or actual failure modes in a system, process, or product; to rank the criticality of the failures by their risk priority; and finally to find improvement method to avoid re-occurrence of the failure mode in future. In estimating the risk due to a failure mode, an index called the RPN (Risk Priority Number) is used, which is obtained by multiplying the ratings of detect ability (D), occurrence $(\mathrm{O})$, and severity $(\mathrm{S})$ of the failure mode. In conventional FMEA based on MILSTD 1629A, attention to rectify quality problems is ranked by the score of corresponding RPN. Implementing corrective action will yield into quality improvement ratio as a result of reduction on the ratings of RPN components. The work products of relevant activities will be archived for organizational learning. 
Although using the RPN as basis to rank attention to curb the root cause of business problems is beneficial for practical purposes, perhaps due to its simplicity; in our opinion, it possesses some limitations such as:

- The use of the RPN as multiplication of O, S, and D ratings is unable to consider that the possibility of loss due to failure occurrence may escalate over time started from the detection time of the occurrence of failure cause. In other words, it is ignoring time dimension in quantifying priority of corrective action.

- Conventional FMEA which uses the RPN as basis to rank an improvement effort of business operation is overlooking the possibility of influence by the business system's environment on the improvement effort itself. Following Wielle et al. (2011), recently, it is important to develop quality management tools which consider the impact of uncertainty of business environments.

- According to Yuniarto's study (2009), FMEA is not tailored as problem-structuring method. This feature will possibly imply that rectification of business problem by FMEA analysis is heavily based on subjectivity and experience of FMEA team(s), varying among different industrial applications.

- As briefly described by Shawney et al. (2011) and Liu et al. (2013), endeavours to improve capability of FMEA, having been practiced for decades, are still focused on improving risk quantification methods by counting the RPNs. As Seyehosseini and Hatefi (2009) have well noticed, failure risk quantification and improvement strategy selection are equally important in risk management discipline. But this reality is almost overlooked by previous FMEA studies.

Motivated by the strategic role of FMEA as a tool for continual improvement in various business management systems such as ISO 9000, QS 9000 and ISO 31000, and limitations on using RPN as the only basis to rank competing improvement efforts, this study is intended to undertake initial survey to the status of improvement strategy selection methods in FMEA. It also aims to develop a classification model of the literatures as basis to determine new research opportunities.

The structure of this paper is presented as follows: in section 2, research methodology used in the study is briefly described. A classification chart and table representing findings from our survey is presented. Section 3 relates to the analysis developed from our literature's classification scheme as basis to determine research gaps. Elaborations on new research roadmaps and conclusions from our study are presented in sections 4 and 5 .

\section{RESEARCH METHODOLOGY}

\subsection{Methodology for Obtaining Relevant Literature}

Regarding possibility that FMEA-based improvement strategy selection literatures are spread in many forms of references, systematic initial survey is undertaken. Following
Ngai et al. (2009), among other types of literature, the periodical is chosen since it is perceived as the source of the most up to date knowledge elaborating on very specific issue. The literature databases such as Emerald, Springer, Ebscohost, Hindawi, Sage, Ingenta, ScienceDirect, IEEExplore, and directory of open access journal (DOAJ) are used. The time span of initial survey is ranging from 2000 to 2013. Literature written in non-English language is skipped. The key words used in the literature search are "FMEA", and "FMECA". The FMEA aspect that we intend to investigate is on improvement strategy selection issue only. The other FMEA scopes such as FMEA automation, modification of FMEA algorithm, appraisal on the magnitude of risk of failure, and enhancement to model cause and effect analysis in FMEA method are excluded in this study.

\subsection{Methodology for Classifying References}

The relevant literatures which fit with our goal are then classified into various groups as depicted in figure 1 . The classification scheme is based on three aspects: i) base attributes as improvement strategy selection criteria, covering economic measure (cost, profit, loss, failure rate occurrence, and scrap reduction),risk measure with major focus on RPN including failure occurrence reduction ratio and other attributes using advanced mathematical tools such as AHP (Analytical Hierarchy Process), ANP (Analytical Network Process), Integer Programming (IP),ii) application context covering companywide and supply chain, and iii) industrial's application area covering manufacturing and service industries. In order to understand the current status of improvement strategy selection based on FMEA, it is important to map relevant literatures to give pictorial view on what studies already exist and what is needed to cope with trend of business situation. Besides, it will be easier to identify the research discrepancies related to selected topics in this study. Realizing that strategy selection model in FMEA has many aspects, we limit our proposal to extend risk-based improvement selection model into 5 aspects only as depicted in figure 1 .

\section{SOME OBSERVABLE GAPS AND THE RATIONALES FOR EXTENDING IMPROVEMENT STRATEGY SELECTION MODELS}

Referring to our preliminary survey on classification criteria, the RPN and the economic metrics (money, time and quality specifications) are the two most commonly used attributes in selecting improvement strategy. See Tables 1 and 2 for relevant works referenced. However, some studies have been devoted to improve limitation on using RPN only as improvement selection basis. For instance, in attempt to deal with multiple goals, the utilization of AHP and Goal Programming is presented by Bertolini and Bevilacqua (2006). ANP is used by Zammori and Gabbrielli (2011) in dealing with interrelationship among corrective actions. Some other works can also be found in Tables 1 and 2. 


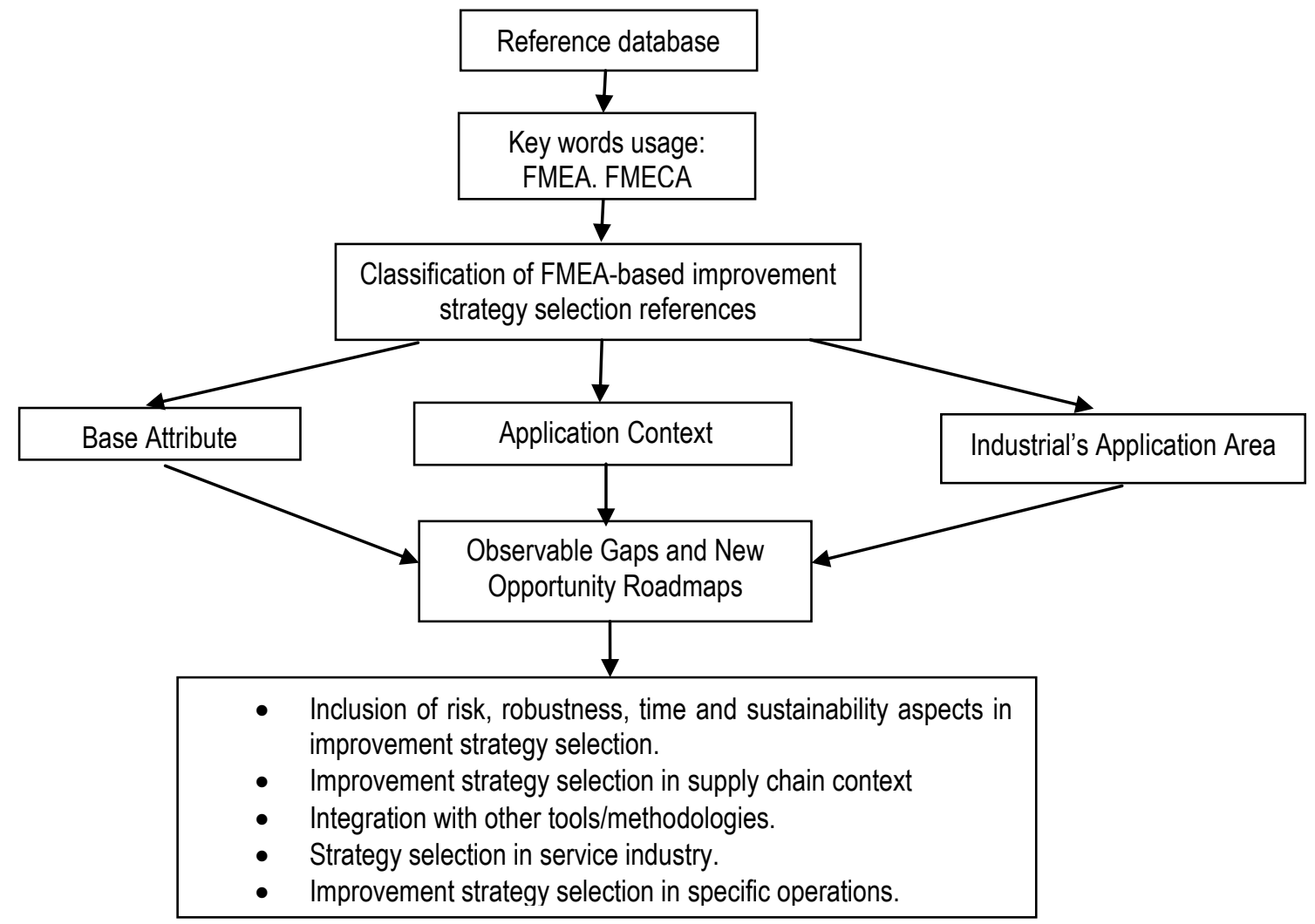

Figure 1. The classification framework of FMEA-based Improvement strategy references

Table 1. Works for FMEA-based corrective action selection in product design and manufacturing industries

\begin{tabular}{|c|c|c|}
\hline \multirow{2}{*}{$\begin{array}{c}\text { Improvement } \\
\text { Selection Criteria }\end{array}$} & \multicolumn{2}{|r|}{ Application Context } \\
\hline & Supply chain & Companywide \\
\hline Economic & Pujawan and Geraldin (2009) & $\begin{array}{l}\text { Karupusamy et al. (2006) } \\
\text { Carmignani (2009) } \\
\text { Childs (2009) } \\
\text { Hekmapatnah et al.(2009) } \\
\text { Niuet al.(2009) }\end{array}$ \\
\hline RPN & $\begin{array}{l}\text { Sinha et al. (2004) } \\
\text { Teng et al. (2006) }\end{array}$ & $\begin{array}{l}\text { Bluvband et al. (2003) } \\
\text { Yadav et al.(2003) } \\
\text { Arvanitoyannis and Varzakas (2009) } \\
\text { Buksa et al. (2010) } \\
\text { Yeh et al. (2011) } \\
\text { Choi and Choi (2012) } \\
\text { Ozilgen (2012) } \\
\text { Vinodh and Santosh (2012) } \\
\text { Mariajayaprakash and Senthilvelan (2013) }\end{array}$ \\
\hline Other Attributes & & $\begin{array}{l}\text { Bevilacqua and Braglia (2000) } \\
\text { Bertolini and Bevilacqua (2006) } \\
\text { Chen (2009) } \\
\text { Zammori and Gabrielli (2012) } \\
\text { Sachdeva et al.(2009) }\end{array}$ \\
\hline
\end{tabular}


Table 2. Works for FMEA-based corrective action selection in service industries

\begin{tabular}{|l|l|l|}
\hline \multirow{2}{*}{$\begin{array}{c}\text { Improvement } \\
\text { Selection criteria }\end{array}$} & \multicolumn{2}{|c|}{ Application Context } \\
\cline { 2 - 3 } & \multicolumn{1}{|c|}{ Supply chain } & \multicolumn{1}{c|}{ Companywide } \\
\hline \multirow{2}{*}{ Economic } & & $\begin{array}{l}\text { Seyedhosseini and Hatefi (2009) } \\
\text { Seyedhosseini et al. (2009) }\end{array}$ \\
\hline \multirow{2}{*}{ RPN } & Kumar (2010) & $\begin{array}{l}\text { Shahin (2004) } \\
\text { Chuang (2007) } \\
\text { Santos and Cabral (2008) } \\
\text { Van Leuven et al. (2009) } \\
\text { Bas (2011) } \\
\text { Inue and Yamada (2011) } \\
\end{array}$ \\
& Kumar et al. (2009) & $\begin{array}{l}\text { Murphy et al. (2011) } \\
\text { Nassimbeni et al. (2012) } \\
\text { Barends et al. (2012) } \\
\text { Cicek and Celik (2013) }\end{array}$ \\
\hline Other Attributes & Astuti et al. (2013) & Davidson and Labib (1998) \\
\hline
\end{tabular}

As to application context, some studies have widened utilization of FMEA in supply chain. For example, Astuti et al. (2013) used advanced mathematical tools such as Interpretive Structural Modelling (ISM) and Fuzzy Logic in agricultural supply chain's context. Our observation indicated that, although the studies on improvement strategy selection in FMEA are also utilized empirically within supply chain context, most efforts are dedicated to profit oriented supply chain's operations. Only the work of Kumar (2010) is dealing within nonprofit oriented context (humanitarian supply chain).We also observed that determination of the corrective action ranking methodology is still based on internal company's failure occurrence. Impact of the business environments as complimentary factor seems to be overlooked in appraising improvement efforts by previous literature.

Previous improvement strategy selection models applied in service industries are seemed to ignore many special characteristics of service in business operation. As stated by Sampson (2002) and Hashim (1984), when a service system is considered for study, its properties such as bi-directionality, simultaneity and interrelationship with its environment should be taken into account. In addition, to our knowledge, the basis to select improvement strategy is still based on the perspective that the occurrence of faulty service is due to service provider's fault. The possibility that service consumers do disservice to service providers in the form of jay customer(s) is overlooked in previous models. Our survey also revealed that most of the risk issues resolved by previous studies are concerned with technical and economical risks. The emerging issues such as social risk due to impact of enterprises' operation on society in global business operation and obsolescence risk are not covered by previous studies. We also indicated that most enhancement endeavors are dedicated to rectifying failures in the first phase of business process lifecycle. The possibility on the occurrences of defectiveness in second and sub-sequent of business operations are overlooked in previous models. In addition, our study also indicated that previous endeavors to rectify business problems are still ignoring on their applications in creative industries such as advertising, broadcasting and film industry. At last, consideration of the risk of business transformation as a result of implementing improvement initiatives seems to be neglected by previous strategy selection references.

The above observable gaps and numerous trends on current business operations demand further researches to make up insufficient studies; on service sectors considering the growing contribution to global economy (Zaman and Anjalin, 2011), on developing quality tools for non-profit operations (Johnston, 2005), on dealing with escalation of global disastrous events and emerging issue of sustainability (Beamon, 2008), on the risk of business transformation ( $\mathrm{Su}$ et al., 2010), on the changing business paradigm to supply chain oriented operation (Williams et al., 2006), on impact of business environment's uncertainty in enhancing quality tools and methodology (Wielle et al., 2011), and on predictions of the future reliability and quality management studies (Zio, 2009, Evans, 2013).

Realizing that the topic on improvement strategy selection is having wide research scopes, we only limit our proposals on five issues as depicted in figure 1. Those issues are: inclusion of additional attributes such as sustainability, robustness and risk; application of strategy selection within supply chain context; integration of other tools such as SWOT analysis, Theory of Constraints (ToC), and TRIZ Method; selecting improvement strategy in service industries; application of strategy selection for non-profit environments such as in humanitarian services and specific operations in mass customization and lean environments. Elaborations on the above issues will be briefly described in section 4. 


\section{IMPROVEMENT STRATEGY SELECTION MODELS IN FMEA- NEW RESEARCH ROADMAPS}

\subsection{Inclusion of additional attributes in FMEA based Corrective Action Selection models}

\section{Inclusion of Risk and Robustness}

The economic measure is a very useful criterion in proposing corrective action selection in FMEA for reflecting business goals in making profit. An exemplary cost-benefit criterion in appraising improvement initiative can be seen as in Carmignani (2009).Nevertheless, since the outcome of corrective actions and the resources to be spent are still unknown until implementation as Groso et al. (2012) pointed out, the risk factor as manifestation of uncertainty on the outcome of corrective action implementation can't be neglected. Consideration of risk factor with attitude of decision makers in selecting competing corrective actions in FMEA is still unresolved issue for future study. In addition, above mentioned FMEA-based improvement strategy selection models seem to overlook the hindrance variables (noises) which may derail company in reaping its goals by selected corrective actions. Inclusion of robustness in appraising competing improvement efforts based on FMEA study is also still missing in literature.

\section{Inclusion of Flexibility, Time, and Sustainability Dimensions}

Referring to our initial survey, the Iron Triangle aspect (cost, time, and quality specification) is frequently used as bases to appraise competing corrective actions. Nowadays, as companies are also competing in time and demanding flexibility in applying improvement strategy, inclusion of time based competition and flexibility in implementing corrective actions is important but seems to be overlooked by previous studies. Furthermore, as Thawesaengskulthai (2010) noticed, how to consider corrective action's relevancy measure is important along with financial and technical efficiency but still missing in literature. As Bonn and Fisher (2011) corroborate importance of sustainability issue in strategy development due to depletion of natural resources, sustainability oriented improvement is becoming potential improvement issues. Determination and incorporation of sustainability measure and its appropriate model in riskbased improvement effort are still missing and demanding deeper investigations.

\subsection{Improvement Strategy Selection in Supply Chain (SCM) Context.}

Improving methodology to respond the occurrence of supply chain risk incidents is an emerging research area that attracts attention to both academicians and practitioners (Sodhi et al., 2012). Within supply chain context, FMEA has been applied and reported by literatures, such as in Sinha et al.(2004), Teng et al.(2006), Pujawan and Geraldin (2009), Kumar et al.(2009), Kumar (2010), and Astuti et al.(2013). In addition, many studies have also reported on the issue of quantifying and mitigating risks in supply chain context. For example, in attempt to quantify supply chain risk variables, Buscher and Wells (2010) presented a model to quantify lead time deviation. Pujawan and Geraldin (2009) modified Quality Function Deployment and FMEA to mitigate SC risk and select improvement effort. Singhal et al.(2011), emphasized on the role of coordination mechanism and decision making issues in mitigating the risk in SCM. We have several other studies in SCM context such as utilizing decision support tools such as ANP/ AHP (Vanany et al., 2009), developing mitigation strategy to reduce the adverse impact due to the risk of information flow (Tang and Musa, 2011), investigating supply chain risk mitigation in real industrial practices (Collichia and Strozzi, 2012), investigation on the link between risk mitigation strategy and risk behavior of decision makers (Ghadge et al.,2012), establishment of model to utilize the concept of human immunity against adverse effect from its environment by Srinivasan (2010). But they are not still reaching its maturity stage and demanding more attentions.

As companies are collaborating with others, when non conformities are occurred, contribution of business collaborators is inevitably needed for rectification. Under such situation, the business owner needs to consider capability of business collaborator to collaboratively rectify non conformities. Unfortunately, our survey did not find any studies intended to develop improvement effort selection model which considers collaborator's capability, ownership of responsibility and a metric to measure partners' responsibility in supply chain context.

\subsection{Integration with other tools/Methodology}

\section{Integration with SWOT Analysis}

In running their operation, companies may receive both of positive and negative impacts from their business environments. SWOT analysis can be defined as strategy selection tool based on scanning of business environmental situation. By incorporating SWOT analysis, company can determine appropriate strategy selection based on favorable and unfavorable of business factors from company's inner and outer business environment. In spite of the fact that many studies have already utilized SWOT analysis in strategy development; the references are very scanty on elaborating the inclusion of SWOT Analysis as supporting tool to incorporate impact of business environments in appraising risk-based improvement efforts. Using AHP as means to estimate the weight on impact factor of SWOT variables and assuming independence among SWOT variables, Sutrisno and Kwon (2012) presented a model on integrating SWOT analysis in appraising competing improvement efforts. Extensions on their study may be possible by deleting independence of SWOT variables, delineating numerous amounts of SWOT variables, and considering time in developing improvement strategy selection model as suggested by Helms and Nixon (2010).

\section{Integration with Theory of Constraints (TOC)}

Upon performing FMEA session, numerous options of potential corrective actions are possibly existent. Since company has limited resources in implementing improvement effort, the importance on using the TOC (Theory of constraint) in screening competing corrective action is undeniable. Although references on utilizing TOC for managing business is abundantly available as elaborated by Blackstone (2001) and Rahman (2002), their studies are 
silent on showing the existence on utilization of $\mathrm{ToC}$ in screening competing FMEA-based corrective actions' selection method. Next, regarding possibility that company constraint are consisting both of financial and non financial criteria, establishment of financial and non financial-based TOC as means to select competing improvement efforts are still absent in reference.

\section{Integration with TRIZ Method}

Finding the root cause of service quality problem in a fast and objective manner is important for improving business operation. Our survey to previous FMEA studies is indicating that brainstorming is used most frequently to identify the root cause and potential solution to curb the root cause of quality problem. The use of brainstorming, however, is heavily depending on team subjectivity and experience of the FMEA's members. The TRIZ Method may provide a good option in bridging this discrepancy, there is a need to improve corrective action selection based on. The integration of FMEA and TRIZ studied by Hua et al. (2006) is still limited to their empirical application to non service oriented application. Endeavor to utilize TRIZ method in rectifying business problem in service operation is still missing in references.

\section{Utilization of System Engineering Method}

The re-occurrence of faulty operation in some practical situations can be due to partial approach in viewing problem occurrence from technical perspective only. The additional variables such as organizational and social variables may also contribute to cause of faulty operations. According to Bea et al.(2009), causal factors that may contribute to faulty operations are intersection among technical, social, organizational and physiological variables. And negligence on above variables may inhibit effective failure alleviation. In such situation, a holistic and systematic approach to solve re-occurrence of quality problems shall be accomplished by viewing quality problem rectification process from system's perspective. The utilization of system engineering as basis to formulate holistic and systematic risk mitigation strategies, considering the role of all organizational functions of a company, can prevent the "void" which may trigger the root cause of the problem re-occurrence. However, our survey indicated that the existence of such approach for alleviating quality problems in FMEA literature is vacant. Establishment of a holistic and systematic approach in mitigating risk, taking interrelated roles among organizational units into account within FMEA methodology, is still unanswered and warrants for deeper investigations.

\section{Integration of Game Theory}

Competition is an inseparable part in company's business operation. And regarding this situation, consideration on competitors' reaction upon faulty business assessment using FMEA is important but seems to be overlooked by previous FMEA investigation. In this regards, utilization of Game Theory in selecting competing improvement efforts is still less explored issue in appraising risk-based competing improvement selection model.

\subsection{Improvement Strategy Selection Model in Service Industries.}

Due to the bi-directionality characteristics, the role of customers as co-producers in rectifying business problems in service industries cannot be neglected. Extending elaboration of Hesley and Utley (2011) and Uzkurt (2011), development of a quantitative and qualitative model for quantifying input from customers' participation in rectifying faulty business operation is also urging further investigations. Besides, considering that emotional aspect is naturally accompanying customers' involvement in improving service operation, utilization of Kansei Engineering in proposing improvement strategy is still becoming un-established research area and warrant for deeper investigation.

\subsection{Strategy Selection in Specific Risks / Environments}

\section{Improvement Strategy Selection in Non-profit Environment}

Driven by growing of disastrous events due to act of God and human made disasters in terms of their numbers, the importance in delivering high performance operation in nonprofit operation such as disaster relief is undeniable. According to Oloruntoba and Gray (2009), the model, quality expectation and structure of tiers in humanitarian supply chain operations are different from those in profit oriented supply chain. While some ideas have presented riskbased strategy selection in profit oriented operation as shown in table 1 , the situation is the opposite in non-profit operation. Regarding many differences with profit oriented supply chain operation, many research propositions are waiting for deeper investigations in non-profit operation such as determination of appropriate severity scale in RPN estimation in crisis situation, utilization on non financial metrics in ranking priority of corrective actions.

\section{Improvement Strategy Selection in Mass Customization Environment}

Brabazon and MacCarthy's study (2007) noticed that FMEA as a quality problem assessment tool is mostly used in rectifying quality problems at functional level. Consequently, improvement strategy selection produced by FMEA is possibly applicable at functional level only. Driven by the emerging business philosophy, implication to enhance current FMEA-based improvement strategy selection in mass customization environment is becoming inevitable. In attempt to produce customized quality problems' solution, FMEA team may consult to their customers. Involving customers in solving quality problems in mass customization environment can be facilitated by modifying Quality Function Deployment (QFD) into house of reliability (HoR) as exemplified by Braglia et al. (2007). Nevertheless, establishment of a model which integrated QFD and FMEA in solving quality problems in mass customization environment is still missing in references. 


\section{Improvement Strategy Selection in Lean Environment}

Lean production system is an emerging business paradigm intended to reduce any waste in serving business to the customers. In attempt to create and sustain lean system, reliability of lean system is an important issue to be considered. Apart from study on framework development of lean system (Anand and Kodali, 2010) and identification of problems in lean implementation (Staudacher and Tantardini, 2012), study relating to applying risk management tool in lean environment is very few. Pioneering investigation in accessing reliability of lean system, Shawney et al. (2010) presented the modification of FMEA by presenting the RAV (Risk Assessment Value) model as basis to rank the risk in lean operation system. However, empirical investigation on the risk appraisal from transforming business organization into lean environment and selection of tools to rectify problems from above transformation are nonexistent in the literature.

\section{Risk Mitigation for Obsolescence Risk}

Observing previous risk-based improvement strategy selection model, most studies seem to be based on the risk due to faulty in product design and process operation. Existence of other types of risk due to elapsed system mission time (the obsolescence risk) is overlooked. According to Rojo et al. (2010), for some special sectors such as equipment sales service with very long life cycle span like in aerospace manufacturing and defense industries, the risk of obsolescence is inevitable and the practitioners are taking step to mitigate it in reactive manner. In addition, they proposed a framework for mitigating obsolescence risk within 3 main areas; supply chain, design and planning. Nevertheless, a holistic model to mitigate the risk of obsolescence by taking into account of the cost of obsolescence and the role of suppliers in its mitigation is remained being an open research question.

\section{CONCLUSIONS}

In this paper, an initial survey of studies pertaining to FMEA-based strategy selection methodology is presented. In spite of the fact that many studies have already presented various models to improve quality of above issue, due to the change of business paradigms and the impact of uncertainty of business situations, improvement of the FMEA-based strategy selection methodology is still becoming open area for further investigations. Based on our survey, some new research roadmaps pertaining reprioritization of FMEAbased improvement strategy selection are proposed. We hope that this study will narrow down research discrepancies on risk-based improvement strategy selection in the body of knowledge and becoming a path to undertake further empirical studies in rectifying business problems in various industrial settings.

Since this study is based on limited references, obviously some important issues are escaped from our attentions. Therefore, replication of this primitive study is encouraged with use of other types of literature and additional reference databases. Realizing that our ideas are limited by spaces, the discussions on risk-based improvement strategy selection are extendable to some other issues such as:

- Development of risk-based improvement selection model within virtual environment.

- Mitigation strategy dealing with the risk due to the No Fault Found (NFF) phenomena.

- Establishment of model on linking risk-based improvement strategy selection with business performance management tool such as Balanced Scorecard (BSC) and Customer Relationship Management (CRM), and Change Management model.

- Development of strategy improvement model considering employees' commitment toward company's goal.

- Risk mitigation strategy to reduce adverse impact to social risk by using contemporary method such as Corporate Social Responsibility (CSR) and strategy selection in creative industries' settings.

\section{REFERENCES}

Anand, G. and Kodali, R.(2010), Development of a Framework for Implementing Lean Manufacturing Systems, International Journal of Management Practices, 4(1), pp. 95-116.

Arvanitoyannis, I. S. and Varzakas, T. H. (2009), Application of ISO 22000 and FMEA for Industrial Processing of Salmon: A Case Study, Critical Reviews in Food Science and Nutrition, 48(5),pp. 411-429.

Astuti, R., Marimin, Machfud, Arkeman, Y., Poerwanto, R., and Meuwissen, M.P.M. (2013), Risks and Risks Mitigations in the Supply Chain of Mangosteen: A Case Study, Operations and Supply Chain Management, 6(1), pp.11-25.

Bea, R., Mitroff, I., Farber, D., Foster, H., and Robert, K.H. (2009), A New Approach to Risk: The Implications of E3, Risk Management, 11(1), pp.30-43.

Beamon, B. (2008), Sustainability and the Future of Supply Chain Management, Operations and Supply Chain Management, 1(1), pp.4-18.

Bertolini, M. and Bevilacqua, M. (2006), A Combined Goal Programming- AHP to Maintenance Selection Problem, Reliability Engineering and System Safety, 91, pp.893848.

Bevilacqua, M. and Braglia, M. (2000), The Analytic Hierarchy Process Applied to Maintenance Strategy Selection, Reliability Engineering and System Safety, 70, pp. 71-83.

Blackstone, J. H. (2001), Theory of Constraint - A Status Reports, International Journal of Production Research, 39(6), pp. 1053-1080.

Bluvband, Z., Grabov, P., and Nakar, O. (2004), Expanded FMEA (EFMEA), in Proceedings of the Annual Symposium on Reliability and Maintainability, pp. 3137.

Bonn, I. and Fisher, J. (2011), Sustainability: The Missing Ingredient in Strategy, Journal of Business Strategy, 32(1),pp.5-14.

Brabazon, P.G. and MacCarthy, B. (2007), Consideration of the Relevance of Standard Quality Techniques in Mass Customization, International Journal of Mass Customization, 2(1/2), pp.76-94. 
Braglia, M., Fantoni, G., and Frosolini, M. (2007), The House of Reliability, International Journal of Quality and Reliability Management, 24(4), pp. 420-440.

Buksa, T., Pauline, D., and Sokovic, M. (2010), Shipbuilding Pipeline Production Quality Improvement, Journal of Achievement in Materials and Manufacturing Engineering, 40(2), pp.160-166.

Buscher, U. and Wels, A.(2010), Supply Chain Risk Assessment with the Functional Quantification on Lead Time Deviation, International Journal of Integrated Supply Management, 5(3), pp.197-213.

Carbone, T.A. and Tippet, D. D. (2004), Project Risk Management Using the Project Risk FMEA, Engineering Management Journal, 16(4),pp.28-35.

Chuang, P.T. (2007), Combining Service Blueprint and FMEA for Service Design, The Service Industries Journal, 27(2), pp.91-104.

Carmignani, G. (2009), An integrated Structural Framework to Cost-based FMEA; The Priority Cost FMEA, Reliability Engineering and System Safety, 94(4), pp.861-871.

Chakravorthy, S. S. (2012), Prioritizing Improvement Projects: Benefit and Effort (B\&E) Analysis, Quality Management Journal, 19(1), pp.24-33.

Chen, J. K. (2007), Utility Priority Number Evaluation for FMEA, Journal of Failure Prevention, 7, pp.321-328.

Child, J. A. (2009), Turning Multiple Process FMEA Results into an Optimal Action Plan, Proceedings of the 2009 Annual symposium on Reliability and Maintainability, Forth Worth, Texas, pp.412-416.

Choi, H.G. and Choi, D. (2012), Framework Development for Optimizing Responses to New Product Development Risks, International Journal of Management Science and Engineering Management, 7(3),pp.229-240.

Cicek, K. and Celik, M. (2013), Application of FMEA to Main Engine Cranckcase Explosion Failure on-Board Ship, Safety Science, 51, pp.6-10.

Colicchia, C. and Strozzi, F. (2012), Supply Chain Risk Management: A New Methodology for A Systematic Literature Review, Supply Chain Management: An International Journal, 17(4), pp. 403-418.

Davidson, G. and Labib, A.W.(1998), Learning from Failures: Design Improvement Using Multiple Criteria Decision Making Process, Proceedings of the Institution of Mechanical Engineers part G., Journal of Aerospace Engineering Part G, pp. 207-216.

Devadasan, S. R., Muthu, S., Samson, R. N., and Sankaran, R. A. (2003), Design of Total FMEA Programme, International Journal of Quality and Reliability Management, 20(5),pp.551-568.

Evans, J.R. (2013), Insights on the Future of Quality Management Research, Quality Management Journal, 20(1), pp.48-55.

Ghadge, A., Dani, S., and Kalawsky, R. (2012), Supply Chain Risk Management: Present and Future Scope, International Journal of Logistics Management, 23(3), Early View Edition.

Groso, A., Ouedraogo, A., and Meyer, T. (2012), Risk Analysis in Research Environment, Journal of Risk Research, 15(2), pp.187-208.
Hashim, M. (1984), Reliability Concepts Applied to Service Industries, International Journal of Quality and Reliability Management, 1(1), pp.39-50.

Hekmapatnah, M., Shahin, A., and Ravichandran, N. (2011), The Application of FMEA in the Oil Industry in Iran: The Case of Four Litter Oil Canning Process of Sepahan Oil Company, African Journal of Business Management, 5(7), pp.3019-3027.

Helms, M.M. and Nixon, J. (2010), Exploring SWOT Analysis - Where Are We Now?: A Review of Academic Research from the Last Decade, Journal of Strategy and Management, 3(3), pp.215-251.

Hensley, R.L. and Utley, J.S. (2011), Using Reliability Tools in Service Operations, International Journal of Quality and Reliability Management, 28(5),pp.587-593.

Hua, Z., Yang, J., Coulibaly, S., and Zhang, B. (2006), Integrating TRIZ with Problem- Solving Tools: A Literature Review from 1995 to 2006, International Journal of Business Innovation and Research, 1(1/2), pp.111-128.

Inoue, H. and Yamada, S. (2010), FMEA in Pharmaceutical Research, International Journal of Quality and Service Sciences, 2(3), pp.369-382.

Johnston, R.(2005), Service Operation Management: From the Roots Up, International Journal of Operations and Production Management, 25(12), pp.1298-1308.

Karuppuswamy, P., Sundararaj, P., Devadasan, S.R., Elangovan, D., and Savamuthu, L. (2006), Failure Reduction in Manufacturing System Through The Risk Management Approach and The Development of A Reactive Maintenance Model, International Journal of Risk Assessment and Management, 6(4/5/6), pp. 545564.

Kumar, S. (2010), Managing Risks in a Relief Supply Chain in the Wake of an Adverse Events, Operational Research Insight, 24, pp.131-157.

Kumar, S., Dieveney, E., and Dieveney, A. (2009), Reverse logistic Process Control measures for the Pharmaceutical Industry Supply Chain, International Journal of Productivity and Performance Management, 58(2), pp.188-204.

Liu, H.C., Liu, L., and Liu, N. (2013), Risk Evaluation Approaches in FMEA: A Literature Review, Expert Systems with Applications, 40, pp.828-838.

Mariajayaprakash, A. and Senthilvelan, T. (2013), Failure Detection and Optimization of Sugar Mill Boiler Using FMEA and Taguchi Method, Engineering Failure Analysis, 30, pp.17-26.

Murphy, M., Heaney, G., and Perera, S. (2011), A Methodology for Evaluating Construction Innovation Constraints Through Stakeholders Competencies and FMEA, Construction Innovation: Information, Process, Management, 11(4), pp. 416-440.

Nassimbeni, G., Sartor, M., and Dus, D.(2012), Security Risks in Service Off shoring and Outsourcing, Industrial Management and Data Systems, 112(3), Npp.405-440.

Ngai, E.W.T., Xiu, L., and Chau, D.C.K. (2009), Application of Data Mining Techniques in Customer Relationship Management: a Literature Review and Classification, Expert Systems With Application, 36, pp. 2592-2602. 
Niu, Y.M., He, Y.Z., Li, J.H., and Zhao, X.J.(2009), The Optimization of the RPN Criticality Analysis Method in FMECA, in Proceedings of the International Conference on Apperceiving Computing and Intelligent Analysis, Shanghai, pp.166-170.

Oloruntoba, R. and Gray, R.(2009), Customer Service in Emergency Relief Chains, International Journal of Physical Distribution and Logistics Management, 39(6), pp.486-505.

Ozilgen, S. (2012), FMEA for Confectionery Manufacturing in Developing Countries: Turkish Delight Production as a Case Study, Ciencia e Technologia Alimentos, 32(3), pp.505-514.

Pujawan, I N., and Geraldin, L.H. (2009), House of Risk: a Model for Proactive Supply Chain Risk Management, Business Process Management Journal, 15(6), pp. 953967.

Rahman, S. (2002), Theory of Constraints: A Review of the Philosophy and Its Application, International Journal of Operations and Production Management, 18(4), pp.336-355.

Rojo, F. J. R., Roy, R., and Shehab, E. (2010), Obsolescence Management for Long Life Contracts: State of The Art and Future Trends, International Journal of Advanced Manufacturing Technology, 49, pp. 1235-1250.

Sachdeva, A., Kumar, D., and Kumar, P. (2009), MultiFactor Failure Mode Criticality Analysis Using TOPSIS, Journal of Industrial Engineering International, 5(8), pp.1-9.

Sampson, S. E. (2000), Customer-Supplier Duality and Bidirectional Supply Chains in Service Organizations, International Journal of Service Industry Management, 11(4), pp. 348-364.

Santos, F. R. S. and Cabral, S. (2008), FMEA and PMBOK Applied to Project Risk Management, Journal of Information Systems and Technology Management, 5(2), pp.1807-1775.

Sawhney, R., Subburaman, K., Sonntag, C., Rao, P. R. V., and Capizzi, C. (2010), A Modified FMEA Approach to Enhance Reliability of Lean Systems, International Journal of Quality and Reliability Management, 27(7), pp.832-855.

Seyedhosseini, S.M. and Hatefi, M.A. (2009), Two Pillar Risk Management (TPRM): a Generic Project Risk Management Process, Scientia Iranica Transaction E: Industrial Engineering, 16(2), pp.138-148.

Seyedhoseini, S.M., Noori S., and Hatefi, M.A.(2009), An Integrated Methodology for Assessment and Selection of the Project Risk Response Actions, Risk Analysis, 29(5), pp.752-762.

Singhal, P., Agarwal, G., and Mittal, M.L. (2011), Supply Chain Risk Management: Review, Classification and Future Research Directions, International Journal Business Science and Applied Management, 6(3), pp.15-42.

Sinha, P.R., Whitman, L.E., Malzahn, D. (2004), Methodology to Mitigate Supplier Risk in An Aerospace Supply Chain, Supply Chain Management: An International Journal, 9(2), pp.154-158.

Sodhi, M. S., Son, B.G., and Tang, C.S. (2012), Researcher's Perspective on Supply Chain Risk Management, Production and Operations Management, 21(1), pp.113.
Srinivasan, R.S. (2010), Supply Chain Immunity: a Methodology for Risk Management, International Journal of Service Sciences, 3(1), pp.1-20.

Staudacher, A.P. and Tantardini, M. (2012), Investigating the Main Problems in Implementing Lean in Supply Chain of Service Companies, International Journal of Service and Operations Management, 11(1), pp.87-106.

Su, N., Akkiraju, R., Nayak, N., and Goodwin, R. (2010), Business Transformation under Uncertainty: Understanding the Value of Strategic Flexibility, International Journal of Service Operations and Informatics, 5(1), pp.53-63.

Sutrisno, A. and Kwon, H.M. (2012), Corrective Action Strategy based on SWOT Analysis in Service FMEA, Journal of Korean Society of Quality Management, 40(1), pp.25-36.

Tang, O. and Musa, S. N. (2011), Identifying Risk Issues and Research Advancements in Supply Chain Management, International Journal of Production Economics, 133, pp. 25-34.

Teng, S. G., Ho, S. M., Shumar, D., and Liu, P. C. (2006), Implementing FMEA in Collaborative Supply Chain Environment, International Journal of Quality and Reliability Management, 23(2), pp. 179-196.

Thawesaengskulthai, N. (2010), An Empirical Framework for Selecting Quality Management and Improvement Initiatives, International Journal of Quality and Reliability Management, 27(2), pp. 156-172.

Uzkurt, C. (2010), Customer Participation in Service Process: a Model and Research Preposition, International Journal of Service and Operations Management, 6(1), pp.17-37.

Van Leeuwen, J.F., Nauta,M. J., de Kaste,D., OdekerkenRombouts, Y.M., Oldenhof, M.T., Vredenbregt,M.J., and Barends, D.M. (2009), Risk Analysis by FMEA as an Element of Analytical Validation, Journal of Pharmaceutical and Biomedical Analysis,50(5), pp.1085-1087.

Vanany, I., Zailani, S., and Pujawan, N. (2009), Supply Chain Risk Management: Literature Review and Future Research, International Journal of Information Systems and Supply Chain Management, 2(1), pp.16-33.

Vinodh, S. and Santosh, D. (2012), Application of FMEA to an Automotive Leaf Spring Manufacturing Organization, The TQM Journal, 24(3), pp.260-274.

Wiele, T.V., Iwaarden, J.V., Williams, R., and Eldridge, S. (2011), A New Foundation for Quality Management in the Business Environment for the Twenty First Century, Total Quality Management and Business Excellence, 22(5), pp.587-598.

Williams, R., Wielle, T. V. D., Iwaarden, J. V., Bertsch, B., and Dale, B. (2006), Quality Management: The New Challenges, Total Quality Management and Business Excellence, 17(10),pp. 1273-1280.

Yadav, O.P., Singh, N., Chinnam, R.B., and Goel, P.S. (2003), A Fuzzy Logic based approach to reliability improvement estimation during product development, Reliability Engineering and System Safety, 80(5), pp.273-278.

Yeh, C., Liu, W.C., and Lee, C.L. (2011), Risk Assessment and Action Selection in Preliminary Design, International Journal of Innovation and Technology Management, 8(1), pp.77-94. 
Yuniarto, H.A. (2009), The Shortcomings of the Existing Root Cause Analysis Tools, Proceedings of the World Congress of Engineering2012 Volume III, London, UK.

Zaman, A.S.M. and Anjalin, U. (2011), Evolution of Service: Importance, Competitiveness, and Sustainability in the New Circumstances, Journal of Service Science and Management, 4(3), pp.253-260.
Zammori, F. and Gabbrielli, R. (2012), ANP/RPN: A Multi Criteria Evaluation of the RPN, Quality and Reliability Engineering International, 28(1), pp. 85-104.

Zio, E. (2009), Reliability Engineering: Old Problems and New Challenges, Reliability Engineering and System Safety, 94, pp.125-14.

Agung Sutrisno is lecturer at Department of Mechanical Engineering, Sam Ratulangi University, Manado, Indonesia. He obtained his B.Eng and M.Eng degree in Metallurgical and Material Engineering and Manufacturing Engineering from University of Indonesia in 1999and 2001. His PhD is obtained from Pukyong National University, Busan, South Korea in 2012. His research interests are in quality, reliability, maintenance, operation, safety, and service engineering.

Hyuck Moo Kwon is a professor at Department of Systems Management and Engineering at Pukyong National University, Busan, South Korea. He obtained his Bachelor in Business Administration at Seoul National University, Master and PhD in Industrial Engineering at KAIST (Korean Advanced Institute of Science and Technology). He has published papers in numerous journals such as Naval Research Logistics, European Journal of Operational Research, International Journal of Production Research, IIE Transaction, International Journal of Quality, Reliability and Safety Engineering and International Journal of Production Economics. His research interests are in Quality, Reliability, Safety, Six Sigma and Service System.

Tzong-Ru (Jiun-Shen) Lee is a professor of Marketing Department at National Chung - Hsing University in Taiwan. He obtained his bachelor and master Degree in Industrial Engineering from National Chiao Tung University, Taiwan. His PhD is obtained from Texas A\&M University, USA. He is a 2006 Fulbright visiting professor in USA and a joint author of four books. His researches mainly focus on SCM, CRM, Marketing, Electronic Commerce, Risk Management, and Business Ethics. His papers have been published in various journals such as Supply Chain Management: an International Journal, Journal Manufacturing Technology Management, International Journal of Service and Operations Management, International Journal of Logistics Systems and Management, International Journal of Service Technology Management and International Journal of Value Chain Management.

Jang Hyon Ae is a PhD Student at Pukyong National University. She obtained her master degree from Department of Systems Management and Engineering, Pukyong National University, Busan, South Korea in 2010. Her research interests are in Quality Management and Service System. 